\title{
PUBLIC AUTHORITIES' ROLE IN PUBLIC EDUCATION ORGANIZATION IN THE SIMBIRSK PROVINCE IN THE SECOND HALF OF THE 19TH CENTURY
}

(C) 2017

\author{
Aizatullova Alsu Shamilievna, candidate of historical sciences, \\ associate professor of Humanities and Social Sciences Department \\ Ulyanovsk Institute of Civil Aviation named after Chief Marshal of Aviation B.P. Bugaev \\ (Ulyanovsk, Russian Federation)
}

\begin{abstract}
This paper examines public authorities' role in public education organization in the Simbirsk province in the second half of 19th - beginning of the 20th century. The state structures, the Russian Orthodox Church and other confessions managed the state-religious education in the country. The author examines the role of public authorities in the organization of state-religious education of people. The Ministry of National Education and the Holy Synod were responsible for it on the state scale. In the provinces this work was coordinated by the guardianship of the school districts, directorate of education and provincial and district councils. In secular educational institutions educational work was organized by the directorate of public schools, who controlled the educational work of school teachers and effective forms and methods use. The main responsibility of the national education directorates was joint Russian-Tatar schools opening, Russian classes opening in Islamic schools and compulsory Russian language study in Tatar schools. An important goal was to tighten control over the school activities. There was Orthodox missionary fraternity. These organizations were responsible for the same questions. Provincial directorates of national education had to coordinate all state-religious activities done by teachers, religious priests and missionaries. Thus, the system of the state-religious education management was complex, diverse; its parts copied each other, so it led to its activity efficiency decrease.

Keywords: education; provincial directorate; Holy Synod; loyal spirit; state government; ministry of education; guardianship school districts; provincial and district school councils; diocese; denominations; directorate of national education; parish; secular schools; Orthodox missionary fraternity.
\end{abstract}

УДК $323.3(470)$

\section{ВСЕРОССИЙСКИЙ СОЮЗ РАВНОПРАВИЯ ЖЕНЩИН В БОРЬБЕ ЗА ВСЕОБЩЕЕ ИЗБИРАТЕЛЬНОЕ ПРАВО В 1905-1907 ГОДАХ}

(C) 2017

Банникова Наталия Федоровна, кандидат исторических наук, профессор кафедры философии и истории Миняшев Виктор Сергеевич, аспирант кафедры философии и истории

Самарский национальный исследовательский университет имени академика С.П. Королёва

(2. Самара, Российская Федерачия)

Аннотация. В статье рассматривается вопрос о политической активности российского общества в начале XX века. Важным направлением этого процесса было усиление женского движения, которое стремилось расширить гражданские и политические права. Показана позиция оппозиционных партий: кадетов, социалдемократов, эсеров, трудовиков, народных социалистов, выступавших за женское избирательное право. В годы первой русской революции появляются новые общественные организации, среди которых видное место занимает Всероссийский союз равноправия женщин. Рассказывается история основания союза. Показаны основные формы работы союза в борьбе за избирательное право для женщин: участие в митингах и собраниях, подготовка петиций и листовок, агитационно-пропагандистская работа, сбор наказов среди крестьянок. Особое внимание уделено агитационной работе членов союза. Показана статистика подписей, собранных под наказами в Государственную Думу с требованием женского избирательного права по отдельным регионам России. Выделены контакты Всероссийского союза равноправия женщин с думской оппозицией, особенно с фракцией социалистических партий и конституционными демократами, показано их тесное взаимодействие. Указаны конкретные депутаты Государственной Думы, наиболее активно сотрудничавшие с Всероссийским союзом равноправия женщин.

Ключевые слова: борьба за женское избирательное право; Всероссийский союз равноправия женщин; Государственная Дума Российской империи; избирательная компания в I Государственную Думу; избирательная компания во II Государственную Думу; партия народной свободы; первая российская революция; социал-демократическая фракция.

Женское движение в России стало активно развиваться в годы революционных потрясений в начале $\mathrm{XX}$ столетия. В это время в стране формировались многие общественные организации, в том числе женские. До 1905 года женщины в основном выступали за доступ к высшему образованию и профессиональному труду, теперь они включились в борьбу за политические права. В исторической литературе дея- тельность Всероссийского союза равноправия женщин (ВСРЖ) исследована недостаточно. ВСРЖ был первой организацией, которая боролась за предоставление избирательных прав женщинам, за активное участие в решении социальных вопросов.

В период разработки избирательного закона в начале 1905 года членами ВСРЖ была подготовлена и распространена листовка, в которой они обраща- 
лись к сторонникам женского равноправия в «Союзе освобождения» и участников земских съездов о необходимости распространения идеи всеобщего, равного, прямого и тайного избирательного права на женщин. В листовке отмечалось: «Простая логика и элементарная справедливость требуют, чтобы под словами «всеобщее и равное для всех» подразумевались одинаково как мужчины, так и женщины» [1, л. 12]. Состоявшемуся 2 мая 1905 года съезду представителей земств и городов было послано свыше 50 заявлений с сотнями подписей от женщин различных городов России с требованием предоставления им избирательных прав. Однако эти заявления не были рассмотрены, потому что сам вопрос об избирательных правах женщин был снят с очереди, но бюро съезда под давлением этих требований подготовило благоприятную для женщин резолюцию, и 68 членов съезда подали мотивированное заявление о необходимости немедленного рассмотрения этого вопроса в целях удовлетворения требования женщин. В результате бюро съезда подготовило специальную резолюцию по женскому вопросу [2, л. 1].

7-10 мая 1905 года в Москве было проведено Учредительное собрание Всероссийского союза равноправия женщин. Секретарем Центрального бюро была избрана М.А. Чехова. На съезде ВСРЖ был утвержден устав союза, который содержал идейную платформу и задачи организации. «Сейчас же нет такой сферы научного или практического труда - педагогической, врачебной, литературной, общественной, где бы женщина не доказала своей работоспособности и политического самосознания» [2, л. 20], - подчеркивалось в резолюции бюро союза.

В съезде участвовали делегаты от групп, образовавшихся к этому времени в 28 городах. Было выбрано центральное бюро и делегация в Союз союзов. Главной целью ВСРЖ была борьба за политическое равноправие женщин, то есть за всеобщее, равное, прямое и тайное избирательное право без различия пола. Съезд призвал к бойкоту Булыгинской Думы [3].

Бурную критику в российском обществе вызывала сама система выборов в Государственную Думу. Архивные материалы свидетельствуют о том, что ВСРЖ посылал своих агитаторов в другие города и даже в сельскую местность, создавая там отделения союза из крестьянок. На местах составлялись петиции в органы местного самоуправления и в Государственную Думу с требованием активнее отстаивать женское избирательное право [1, л. 64]. Женщины Москвы в 1905 году подали петицию с тысячью подписей в городскую Думу с требованием предоставления женщинам избирательного права при выборах в законодательное учреждение и органы местного самоуправления [3].

2 октября 1905 года Харьковский отдел ВСРЖ направил обращение в Волчанское уездное земское собрание Харьковской губернии. В обращении отмечалось: «Положение о губернских и уездных земских учреждениях приравнивает женщин к несовершеннолетним. Они могут передать свой ценз только ближайшим родственникам. Женское правосознание при непрерывном поступательном росте не может больше мириться с этими ограничениями, которые создаются для женщин упомянутыми положениями.
Земское собрание просили принять резолюцию за женское избирательное право. Указывалось на два несоответствия, возникающих из-за лишения избирательных прав женщины: 1) имущество женщины может включаться в ценз ближайших родственников, которые вольны голосовать, как хотят, не считаясь с мнением владелицы ценза; 2) земства широко используют женский труд во многих сферах деятельности, в частности - в образовании и медицине». Подобные критические положения содержались и в петиции ВСРЖ в Московское губернское земское собрание [1, л. 62-63; 2. л. 14].

О повышении политической активности женщин России свидетельствуют и факты, которые наблюдались в период выборов в I Государственную Думу. Женщины-работницы являлись на избирательные собрания с требованием предоставления им права участия в выборах. В Москве на фабрике Чепелевецкого работницы явились на собрание в таком количестве, что, когда им было отказано в праве участия в голосовании, женщины путем обструкции сорвали выборы. В Вятской губернии в некоторых местах на выборах уполномоченных от волостных сходов для избрания выборщиков фактически приняли участие в голосовании женщины, заменившие отсутствующих мужчин [2, л. 2].

В период выборных кампаний в Государственную Думу ВСРЖ систематически направлял петиции депутатам, в которых подчеркивали необходимость принятия закона о всеобщем, равном, прямом и тайном избирательном праве без различия пола, национальности и вероисповедания. ВСРЖ особое внимание уделял присутствию членов союза на избирательных собраниях для пропаганды своих идей. Но угрозой для свободы слова на избирательных и других собраниях было присутствие членов полиции, наделенных правом закрывать их. Особенно рьяно они выступали против участия женщин на собраниях избирателей. Так, 5 марта 1906 года полицейский закрыл собрание в Санкт-Петербурге, так как председатель собрания кадет М.М. Винавер отказался удалить женщин из зала [4].

Благодаря активной деятельности членов ВСРЖ в ноябре 1905 года отделения Всероссийского союза равноправия женщин действовали уже в 64 городах империи. Крупнейшие из них находились в СанктПетербурге (около 300 членов) и в Москве (около 600 членов).

Члены ВСРЖ занимались не только пропагандой своих взглядов и организацией подачи петиций и митингов. Они много внимания уделяли подготовке и распространению листовок, устройству женских клубов и кружков, собраний, содействовали другим союзам и партиям. Наиболее близкими ВСРЖ были идеи социалистических партий, но союз активно взаимодействовал и с кадетской партией.

Еще в 1903 году в программу РСДРП было включено требование «всеобщего, равного и прямого избирательного права» при выборах как в законодательное собрание, так и во все местные органы самоуправления для всех граждан и гражданок, достигших двадцати лет [5]. Требование всеобщего избирательного права для граждан обоего пола содержали и программы партии социалистов-революционеров и трудовой народно-социалистической партии [6; 7]. 
Банникова Н.Ф., Миняшев В.С.

В первой редакции программы партии народной свободы не было единой позиции об избирательном праве женщин. Это вызвало негодование женщин членов партии кадетов. В итоге II съезд партии народной свободы 5-11 января 1906 убрал из программы примечание, допускавшее разночтение мнений о женском избирательном праве $[8$, с. 36,120 , 179]. Необходимость совершенствования избирательной системы назрела в обществе. Видный представитель левого крыла кадетов юрист М.М. Винавер подчеркивал, что «Россия, конечно, может перенимать опыт стран Запада, но двигаться нужно к более рациональной модели государственного порядка» [9].

Всероссийский союз равноправия женщин поэтому рекомендовал своим отделениям на местах действовать через кадетскую и социалистические партии. В I Государственную Думу была подана петиция с более чем пятью тысячами подписей. О том, что ВСРЖ тесно сотрудничал с думской оппозицией, свидетельствует петиция, распространяемая союзом. Под петицией стояли подписи и депутатов I Государственной Думы: Маклашевского, председателя трудовой группы Жилкина, Буслова, Субботина, Друцкого-Любецкого, Гедлата, Герценштейна, публицистов и идеологов трудовой группы Водовозова и Лутугина, кадетов Анненского и Гессена [1, л. 67a].

Всероссийский союз равноправия женщин стремился сотрудничать с другими женскими организациями. В 1906 году при Всероссийском женском взаимоблаготворительном обществе был создан отдел избирательных прав женщин. С первых дней существования российского парламента этот отдел занимался разработкой петиций за расширение избирательного закона. Не имея женщин-депутатов в Государственной Думе, ВСРЖ и отдел избирательных прав женщин действовали через депутатов-мужчин, через женщин, членов партии кадетов (А.В. Тыркову-Вильямс), представителей прессы (Л.Я. Гуревич).

Они направляли делегации в комиссии Думы, подавали прошения, публиковали и распространяли речи депутатов в защиту женского равноправия. 3 мая 1906 года вторая петиция ВСРЖ с требованием женского равноправия, подписанная в общей сложности четырьмя тысячами женщин, была вручена депутатам I Государственной Думы Е.Н. Кедрину и Л.И. Петражицкому [2. л. 2]. В июне этого года юридическая комиссия ВСРЖ передала проект закона о равноправии женщин. В сопроводительной записке к проекту, подготовленной Л.Я. Гуревич, отмечалось, что право избирать и быть избранными в орган народного представительства является основным вопросом в деле равноправия женщин. Проект ВСРЖ обсуждался в I Государственной Думе, был подан в комиссию. Но, к сожалению, I Государственная Дума была распущена.

В своих листовках ВСРЖ регулярно освещал работу депутатов Государственной Думы и их выступления по вопросу о женском избирательном праве. Особенно депутатов социалистических партий и левых кадетов. В листовках ВСРЖ наряду с поддержкой этих депутатов критиковались позиции правых и тех беспартийных депутатов, которые выступали против женского избирательного права. Так, в одной из листовок критике было подвергнуто выступление беспартийного депутата I Государственной Думы крестьянина Кругликова, который с трибуны парламента заявил, что женщины-крестьянки не хотят избирательного права. В опровержении были даны материалы наказов крестьянок Тверской и Воронежской губерний, которые содержали требование женского избирательного права [1, л. 42].

В предвыборную компанию во II Государственную Думу ВСРЖ действовал более активно, имея опыт работы среди населения. Всероссийский союз равноправия женщин, его местные отделения собрали в 122 городах Российской империи свыше 16 тысяч подписей с требованием предоставления женщинам избирательных прав. Немало листов с подписями женщин было получено из сел и деревень. В петициях ВСРЖ подписей женщин-работниц было больше, чем женщин из образованных слоев. Как отмечалось в резолюции союза «буржуазная косность равно, как и партийные предрассудки, слишком часто мешали им присоединить свои подписи» [2, л. 3].

В деревнях большую помощь в сборе подписей оказывали народные учителя, к которым за помощью обращались агитаторы из ВСРЖ. В одном из донесений молодого крестьянина Саратовской губернии, который участвовал в предвыборной компании, отмечалось, что «у нас в России есть много женщин, стремящихся к осуществлению своих прав, но не знают как... Мне учительница вручила лист № 1038 в Государственную Думу, где справедливо требуют равноправия женщин...» [2, л. 3-4].

Для сбора подписей под обращением во II Государственную Думу ВСРЖ разослал более трех тысяч листов в 1037 адресов. Составленная членами союза петиция была переведена на украинский, польский, литовский, немецкий, якутский и другие языки. Географическое распределение полученных 16173 подписей таково: Европейская Россия - 12942, Прибалтийская - 650, Литва и Польша - 1244, Кавказ 1426, Азиатская Россия - 212. В Европейской России подписи были получены из большинства губерний, кроме Астраханской, Таврической, Калужской, Курской, Симбирской и Витебской. Женщины Орловской губернии отправили отдельное послание с 300 подписями через социал-демократическую фракцию Думы. Польские женщины составили дополнительно свою петицию и собрали несколько тысяч подписей. На национальных языках подписывались немки из Прибалтики, еврейки из Бессарабии, грузинки из Кутаисской губернии, армянки и азербайджанки из г. Баку, г. Кубы и Елисаветопольской губернии [2, л. 4-6].

Посильную помощь женщинам в регионах оказывали местные газеты. Иногда они печатали подписные листы и объявляли сбор подписей через свою редакцию. Всероссийский союз равноправия женщин старался поддерживать тесные контакты с оппозиционными фракциями II Государственной Думы. Так, 2 апреля 1907 года делегация ВСРЖ была принята в кадетской фракции. Председатель фракции П.Д. Долгорукий рассказал делегатам о разрабатываемых избирательных законопроектах. 4 апреля эту делегацию приняли в социал-демократической фракции, на 
встрече присутствовал заместитель председателя фракции большевик Г.А. Алексинский [10]. Представители ВСРЖ вручили депутатам петицию, в которой подчеркивалось, что «в целях проведения в жизнь широких демократических начал необходимо установление политической и гражданской равноправности женщин законодательным путем... Мы твердо верим, что Государственная Дума признает всю важность этого принципа и проведет его в новом законе о выборах в Государственную Думу и местное самоуправление» $[1$, л. 36,64$]$. ВСРЖ был уверен, что Государственная Дума сможет добиться чего-то только при опоре на общественное мнение. Руководство союза приняло решение усилить агитацию за всеобщее, равное, прямое и тайное избирательное право без различия пола, национальности и вероисповедания. Важной формой работы союза кроме подготовки петиций и листовок становится регулярное направление докладчиц и агитаторов в деревню и провинцию [1, л. 11].

Идеи распространения избирательных прав на женщин становились все более популярными в российском обществе. Так, на публичном собрании в Санкт-Петербурге для обсуждения вопроса об избирательных правах женщин в более поздний период деятельности Государственной Думы выступили с докладами бывший министр народного просвещения И.И. Толстой на тему «Чем женщина хуже мужчины?», член ЦК кадетов А.В. Тыркова - «А.П. Философова и ее отношение к женскому равноправию», депутат Государственной Думы А.И. Шингарев «Третья Дума в вопросе о женском равноправии» и другие [11, л. 1].

ВСРЖ был легальной самостоятельной организацией, отстаивающей избирательные права женщин. К сожалению, Всероссийский союз равноправия женщин прекратил свою деятельность после третьиюньского переворота. Проблема женского равноправия осталась нерешенной. На смену ВСРЖ придут новые женские организации с другими задачами. Тем не менее деятельность союза равноправия сви- детельствует о том, что в начале $\mathrm{XX}$ века российское общество было готово к демократизации государственного строя. Члены ВСРЖ видели свою роль в решении важного вопроса: какая будет в России государственная форма правления? Благодаря деятельности ВСРЖ по налаживанию контактов с депутатами Государственной Думы накапливался опыт взаимодействия депутатов с общественными организациями, появилась такая форма работы, как прием руководством думских фракций представителей общественных организаций, которая используется и в настоящее время.

\section{СПИСОК ЛИТЕРАТУРЫ:}

1. Государственный архив Российской Федерации (далее-ГАРФ). Ф. 516. Оп. 1, Д. 4.

2. ГАРФ. Ф. 516. Оп. 1. Д. 7.

3. Войтова Л.В. Женское движение в борьбе за равенство гражданских прав (конец XIX - начало XX столетия) // http:/oaji.net/articles/2014/797-1412947922.pdf.

4. Вестник партии народной свободы. 1906, № 3.

5. Программа Российской социал-демократической рабочей партии // Программы политических партий и организаций России конца XIX - начала XX в. M.,1992.

6. Программа партии социалистов-революционеров // Программы политических партий и организаций России конца XIX - начала XX в. М.,1992.

7. Программа трудовой (народно-социалистической) партии // Трудовая народно-социалистическая партия: Документы и материалы. М., 2003.

8. Съезды и конференции Конституционно-демократической партии. В 3-х т. Т. 1. 1905-1907 гг. М.: Российская политическая энциклопедия (РОССПЭН), 1997. $198 \mathrm{c}$.

9. Treadgold W. The constitutional democrats and the Russian liberal tradition // American Slavis and East European Reriew. Apr., 1951. Vol. 10, № 2 P. 85-86.

10. Вестник народной свободы. 1907, №o 14,15.

11. Отдел рукописей Российской национальной библиотеки. Ф. 781. Оп. 1. Д. 233. Л. 1.

\section{ACTIVITIES OF THE ALL-RUSSIAN UNION FOR WOMEN'S EQUALITY (1905-1907)} (C) 2017
Bannikova Natalia Fedorovna, candidate of historical sciences, professor of Philosophy and History Department Minachev Victor Sergeevich, postgraduate student of Philosophy and History Department Samara National Research University (Samara, Russian Federation)

Abstract. The paper deals with the issue of the political activity of Russian society at the beginning of the 20th century. An important direction of this process was the strengthening of the women's movement, which sought to expand civil and political rights. The position of the opposition parties is shown: the Cadets, Social Democrats, Socialist-Revolutionaries, Trudoviks, people's socialists who advocated women's suffrage. In the years of the first Russian revolution, new public organizations appeared where the All-Russian Union of Women's Equality took a prominent place. The story of the foundation of the union is told. The main forms of the union's work in the struggle for women's right to vote are shown: participation in rallies and meetings, preparation of petitions and leaflets, agitation and propaganda work, collection of instructions among peasant women. Particular attention is paid to the agitation work of the members of the Union. The statistics of the signatures collected under the punishments in the State Duma with the demand of women's suffrage for certain regions of Russia are shown. The contacts of the All-Russian Union of Women's Equality with the Duma Opposition, especially with the fraction of the socialist parties and constitutional democrats, are highlighted, their close interaction is shown. Specific deputies of the State Duma most actively cooperating with the All-Russian Union of Women's Equality are indicated.

Keywords: struggle for women's suffrage; All-Russian Union of Women's Equality; State Duma of the Russian Empire; Electoral company to the First State Duma; Electoral company to the Second State Duma; Party of people's freedom; first Russian revolution; Social Democratic fraction. 